\title{
STOKASTIK ÇOK KRİTERLİ KARAR VERMEDE İKİ YENI YÖNTEM: SMAA- GRİ İLIŞKISEL ANALİZ VE SMAA-DEMATEL-GRİ İLİŞKİSEL ANALİZ
}

\author{
Emel KIZILKAYA AYDOĞAN, Mihrimah ÖZMEN \\ Erciyes Üniversitesi, Mühendislik Fakültesi, Endüstri Mühendisliği Bölümü, 38039 Kayseri \\ ekaydogan@ercives.edu.tr, mihrimah@ercives.edu.tr,
}

(Geliş/Received: 05.12.2014; Kabul/Accepted: 27.08.2015)

\begin{abstract}
ÖZET
Karar vermede bazı durumlarda karar vericiler tercihlerini kesin değerlerle belirtemez veya belirtmek istemeyebilirler. Bu gibi durumlarda stokastik verilerle karar vermemize olanak sağlayan Stokastik Çok Kriterli Kabul Edilebilirlik Analizi (SMAA), literatürdeki çalışmalarda etkin bir şekilde uygulanan karar destek araçlarındandır. Gri ilişkisel analiz (GİA) ise deterministik veri ile çalışan çok kriterli karar verme (ÇKKV) problemlerinin çözümünde kullanılan alternatif ve popüler yöntemlerden birisidir. Yapılan çalışmada, SMAA-2 ile GİA ve SMAA-2 ile DEMATEL-GİA yöntemlerini birleştiren iki yeni yöntem, SMAA-GİA ve SMAADEMATEL-GİA önerilmiştir. Önerilen yöntemlerden SMAA-GİA' daki amaç, GİA' nın belirsiz ve kesin olmayan verilerle başa çıkabilmesini sağlayarak stokastik GİA' yı oluşturmak, SMAA-DEMATEL-GİA' daki amaç ise, stokastik verilerle, kriterlerin birbirlerine olan etkisini, DEMATEL yöntemi ile karar verme sürecine dâhil edebilmektir. Önerilen yöntemler, hem bir gerçek hayat problemine, hem de literatürdeki ilaç fayda risk analizi problemine uygulanmıştır. Sonuçlar göstermektedir ki, SMAA-GİA ve SMAA-DEMATEL-GİA yöntemleri, GİA ve DEMATEL yöntemlerinin stokastik veri ve rasgele ağırlıklar ile güvenilir ve tutarlı çalışmasını, aynı zamanda kriterlerin bağımsız olmadığı durumlarda da basit, hızlı alternatif bir yöntem olarak uygulanabilmesini mümkün kılmaktadır.
\end{abstract}

Anahtar Kelimeler: Stokastik çok kriterli kabul edilebilirlik analizi, gri ilişkisel analiz, DEMATEL

\section{TWO NEW METHOD FOR MULTI CRITERIA STOCHASTIC DECISION MAKING: SMAA-GRA AND SMAA-DEMATEL-GRA}

\begin{abstract}
In decision-making in some cases decision makers cannot or do not want to specify preferences with the exact values. To decide with these stochastic data Stochastic Multi-Criteria Acceptability Analysis (SMAA) is an effectively implemented decision support tool. Grey Relational Analysis (GRA) which is working only with deterministic data, is an alternative and a popular method for multi criteria decision making problem. In this study, two new methods SMAA-GRA and SMAA-DEMATEL-GRA are proposed: combination of SMAA-2 and GRA methods and also combination of SMAA-2 and DEMATEL-GRA. The aim of the article is to provide GRA cope with vague and imprecise data in other words, to establish stochastic GRA. And also with DEMATEL we can take into account relationship criteria with each other in decision making process. The proposed methods are applied to both drug benefit risk analysis problem in literature and a real life problem. The study shows that SMAA-GRA and SMAA-DEMATEL-GRA whose results are significant and consistent GRA and DEMATEL methods could be used with ambiguous and arbitrarily distributed data for weights and criteria measurements.
\end{abstract}

Keywords: stochastic multi-criteria acceptability analysis, grey relational analysis, DEMATEL

\section{GİRIŞ (INTRODUCTION)}

Karar verme süreci, günümüz sosyal ve iş hayatında birden çok kriterle ve çoğu zaman da çelişen kriterlerle daha da karmaşık hale gelmiștir. Karar vericiler, bu gibi durumlarda en iyi alternatifi seçmek için ÇKKV yöntemlerini kullanırlar [1]. ÇKKV seçenek sayısına göre ÇAKV (Çok Amaçlı Karar 
Verme) ve ÇÖKV (Çok Ölçütlü Karar Verme) olarak sınıflandırılır [2]. Ayrıca literatürde ÇÖKV, ÇKKV ile aynı anlamda kullanılabilmektedir. ÇKKV yöntemleri deterministik, stokastik ve bulanık yöntemler olarak da sinıflandırılabilmektedir [3]. Deterministik ÇKKV yöntemlerinde uzmanlara sorulan sorularla ve analitik yöntemler kullanılarak amaçların önemini gösteren ağırlıklar elde edilir [4]. ÇKKV problemlerinde bazı durumlarda; örneğin: karar vericilerin yeterli vakitleri olmadığında, kriterleri karşılaştırırken zorluk yaşadıklarında ya da düşüncelerinin diğer kişilerce bilinmesinden rahatsızlık duyduklarında, tercihlerini belirtmek istemeyip, amaçlar arasındaki önemi açıç̧a ve belirgin bir şekilde ifade edemeyebilirler. Parametreler ve ağırlıkların elde edilemediği bu gibi durumlarda SMAA yöntemi literatürde etkin bir karar destek aracı olarak uygulanabilmektedir. SMAA, belirsiz, muğlak ve kısmen eksik veri içeren ÇKKV problemleri için yakın zamanda geliştirilmiş bir yöntemler ailesidir [5]. SMAA yöntemleri, belirsiz karar değerlerini benzetim ederek, alternatiflerin sıralamasını ve bu sıralamada olmasını sağlayan ağırlık vektörünü belirler. $\mathrm{Bu}$ yöntemler çok kriterli karar destek yöntemi olarak kesin olmayan ve belirsiz bilgi içeren problemlere başarıyla uygulanmaktadırlar [6]. SMAA yönteminin öncüleri "karşılaştırmalı hiper hacim kriteri" yöntemi ile Charnetski (1973) ile Charnetski ve Soland (1978) çalışmalarıdır [7-8]. Bu yöntem, her bir alternatifi en çok tercih edilen yapan çok boyutlu ağırlık uzayının hesaplanmasını temel alır. Bana ve Costa (1986), yapmış oldukları çalışmada alternatifleri belirlerken karar vericiler arasındaki uyuşmazlığı en aza indiren genel uzlaşık kriterini kullanmışlardır. Rasgele ağırlık dağılımı yapısıyla, bu yöntem kısmi tercih bilgisiyle başa çıkabilmektedir [9]. SMAA yönteminin ana amacı tercihleri tanımlayan ağırlıklar uzayı ile alternatiflerin sıralamasını birlikte vermektir [6]. SMAA analizlerinin ana çıtıları, sıra kabul edilebilirlik indisleri, merkezi ağırlık vektörleri ve güvenilirlik faktörleridir. ÇKKV' nin farklı tipteki problemlerini (seçme, sıralama ve sınıflandırma) çözmek için literatürde SMAA' nın birçok varyasyonları kullanılmıştır [10]. SMAA-2 yöntemi ile sıra kabul edilebilirlik indislerine göre alternatifler iyiden kötüye doğru sıralanarak, sıralama problematiğinin modele katılması sağlanmıştır [11]. SMAA-3 yönteminde, SMAA' nin orjinal fayda fonksiyonu yerine, ELECTRE III karar destek sistemindeki yapay kriter uygulanmıştır [12]. SMAA-D yönteminde, fayda fonksiyonu yerine, Veri Zarflama Analizinin etkinlik skoru kullanılmıştır [13]. SMAA-O yönteminde, ordinal ve kardinal kriterlere karşılaştırılabilir şekilde yaklaşılarak, SMAA-2 yöntemi genişletilmiştir [14]. SMAA-P yönteminde beklenti teorisi temel alınmıştır [15]. SMAA-TRI ise ELECTRE-TRI' nın parametre kararlılık analizi için ordinal sınıflama yöntemi olarak kullanılmıştır[16]. TOPSIS yönteminin ideale yakınlık değerlerini SMAA' da fayda fonksiyonu yerine kullanan SMAA-TOPSIS yöntemi de SMAA yönteminin bir varyasyonudur [17]. SMAA yöntemleri, literatürde farklı karar verme durumları ve birçok alanda etkin bir şekilde uygulanmıştır [18-41]. GİA, güncel hayattaki birçok karmaşık çok amaçlı problemde, kesikli veri setleri arasındaki ilişkileri analiz etmede karar vericiler için faydalı ve etkin bir ÇKKV yöntemidir. GİA, gri ilişkisel dereceleri hesaplamak için verinin eksik olduğu sistemleri de dikkate alır. Gri ilişkisel alternatifin karmaşık çoklu performans değeri, ağırlıklandırılmış ortalama gri ilişkisel dereceyi oluşturur [42]. GİA yöntemi, çok fazla boyuta sahip, endüstriyel ve sosyal alanlardaki birçok probleme etkin bir şekilde uygulanabilecek alternatif yöntemlerden birisidir. DEMATEL, kriterleri ve kriterler arası ilişkileri tanımlayan, genel yapıyı ve etki faktörlerini analiz etmede kullanılan sistematik bir yaklaşım ve etkili bir yöntemdir. DEMATEL yönteminin literatürde diğer yöntemlerle birlikte kullanımı söz konusudur. Bai ve Sarkis (2013) çalışmalarında GİA ile DEMATEL yöntemlerini birlikte kullanmışlardır [43]. Bulanık DEMATEL ve ANP yöntemleri personel seçimi problemi için uygulanmıştır [44]. Yapılan çalışmada, basit ve yaygın bir şekilde uygulanılabilmesi mümkün olan, alternatif iki yeni yöntem, SMAA-GİA ve SMAADEMATEL-Gİ' nın, literatüre kazandırılması amaçlanmıştır. Önerilen bu yöntemler, GİA ve DEMATEL yöntemlerinin, ağırlık bilgisi olmadığı durumlarda, rasgele ağırlıklarla uygulanılabilmesinin yanı sıra, karar vericilerin belirsiz kriter değerleri ve stokastik veri ile de çalışılabilmesine olanak sağlamıştır. Ayrıca SMAA yönteminin de, kriterlerin bağımsız olmadığı durumlarda, GİA ve DEMATEL yöntemlerinin avantajlı yönlerini kullanarak, daha güvenilir ve tutarlı sonuçlar vermesini de mümkün kılmıştır. Bölüm 2' de GİA, DEMATEL ve SMAA-2 yöntemleri sırasıyla özetlenmiştir. Bölüm 3 ' te önerilen yöntemler, SMAA-GİA ve SMAADEMATEL-GİA sunulmuştur. Bu bölümleri takiben, önerilen yöntemlerin uygulaması ve SMAA yöntemi ile karşılaştırmasının olduğu bölüm, son bölümde ise sonuç kısmı yer almaktadır.

\section{YÖNTEMLER (METHODS)}

\subsection{Gri İlişkisel Analiz Yöntemi (Grey Relational Analysis Method)}

Gri Sistem Teorisi (GST) ilk olarak Deng tarafindan 1982 yılında "Gri Sistemler ile Kontrol Problemleri" makalesi ile önerilmiştir [45]. Az ya da kesikli bilgi ve belirsizlik durumunda başvurulabilecek bulanık mantığa alternatif disiplinler arası bir yöntem olarak literatüre kazandırılmıştır [42]. GST' nin temel amaçlarından biri gözlem verilerinden elemanlar arasındaki "Gri İlişki" yi ortaya çıkarmaktır. GST alt başlıklarından biri olan GİA kriterler arası karmaşık ilişkilerin bulunduğu karar problemleri için etkin bir yöntemdir. Bu özelliği sayesinde GİA'nın literatürde birçok ÇKKV probleminde diğer yöntemlerle 
bütünleşik veya tek başına uygulamalarına sıkça rastlanmaktadır. Silah seçiminde (2000) Yeh ve Lu, yazılımın etkinliğini belirlemede Song ve diğ. (2005) GİA' yı kullanmıştır [46-48]. He ve Hwang (2007) çalışmalarında hasar tespitine karar vermede sezgisel yöntemler ve GİA ' dan oluşan bir hibrit yapı kullanılmıştır [49]. Xu v.d. (2007) GİA’ yı kullanarak yeniden atama yaklaşımı önermişılerdir [50]. Jadidi v.d. (2008) TOPSIS ile GİA yöntemlerini birlikte uygulamış [51]. Özdemir ve Deste (2009) otomotiv sektöründe tedarikçi seçiminde GİA yöntemini uygulamışlar [52]. Wu ve Luyan (2012) ise AHP ve GİA' yı bütünleşik olarak yatırım projesi kararında uygulamışlardır [53]. GİA yöntemi gri bir sistemdeki her bir alternatif ile kıyas yapılan alternatif (referans) serisi arasındaki gri ilişki derecesini belirler. Çok amaçlı optimizasyonda en yüksek gri ilişkisel dereceye sahip olan alternatif optimaldir. GİA' nın adımları aşağıda özetlenmiştir:

Adım 1: Karar Matrisinin Oluşturulması

$m x n$ 'lik m alternatif $n$ kriterden oluşan karar matrisi

$j=1,2,3, \ldots, n$ ve $i=1,2,3, \ldots, m$

$X_{1}(1) \quad X_{1}(2) \quad \ldots \quad X_{1}(n)$

$X_{2}(1) \quad X_{2}(2) \quad \cdots \quad X_{2}(n)$

$\begin{array}{llll}X_{m}(1) & X_{m}(2) & \ldots & X_{m}(n)\end{array}$

Adım 2: Referans Serisinin Oluşturulması

$X_{0}=\left(X_{0}(1), X_{0}(2), X_{0}(3) \ldots . X_{0}(n)\right.$

$\mathrm{Bu}$ çalışmada referans seri $X_{0}=(1,1, \ldots, 1)$ şeklinde tanımlanmıştır. Amaç referans seriye en yakın alternatifi bulmaktır.

\section{Adım 3: Karar Matrisinin Normalize Edilmesi}

Kriterler büyük olan en iyi, küçük olan en iyi ve nominal olan en iyi olarak üçe ayrılır. Eşitlik (1)'deki matris üç tip kritere göre sırasıyla (3), (4) ve (5) formülleriyle normalize edilerek eşitlik (6)' daki normalize karar matrisi elde edilir.

$$
\begin{aligned}
& x_{i}^{*}(j)=\frac{x_{i}(j)-\min x_{i}(j)}{\operatorname{mak} x_{i}(j)-\min x_{i}(j)} \\
& x_{i}^{*}(j)=\frac{\operatorname{mak} x_{i}(j)-x_{i}(j)}{\operatorname{mak} x_{i}(j)-\min x_{i}(j)} \\
& x_{i}^{*}(j)=1-\frac{\left|x_{i}(j)-x^{0}\right|}{\operatorname{mak} x_{i}(j)-x^{0}}
\end{aligned}
$$

$x^{0}=$ istenilen ideal değeri göstermektedir.

$$
X_{i}^{*}=\begin{array}{cccc}
X_{1}{ }^{*}(1) & X_{1}{ }^{*}(2) & \ldots & X_{1}{ }^{*}(n) \\
X_{2}{ }^{*}(1) & X_{2}(2) & \ldots & X_{2}(n) \\
X_{m}(1) & X_{m}(2) & \ldots & X_{m}(n)
\end{array}
$$

Adım 4: Her bir $x_{i}(j)$ ' nin referans noktasına uzaklığını denklem (7) ile hesaplanır.

$\gamma_{0 i}=\frac{\Delta \min +\xi \Delta \max }{\Delta_{0 i(j)}+\xi \Delta \max }$

$\Delta_{0 i(j)=\left|X_{0(j)-} x_{i}^{*}(j)\right|}$

$\Delta \max =\max _{i} \max _{j} \Delta_{0 i(j)}$

$\Delta \min =\min _{i} \min _{j} \Delta_{0 i(j)}$

$\xi \in[0,1]$ katsayısı veri dizisindeki en uç değeri küçültmek için kullanılır ve genelde 0,5 olarak alınır.

Adım 5: Her bir alternatif için gri ilişkisel analiz derecesinin hesaplanması kriter ağırlıkları $\left(\mathrm{W}_{\mathrm{i}}\right)$ iken gri ilişkisel derece $r_{o i}$ denklem (11) ile hesaplanır.

$r_{0 i}=\sum_{j=1}^{n}\left[W_{i}(j) \gamma_{0 i}(j)\right]$

Çok kriterli karar vermede bir alternatif en yüksek $r_{o i}$ değerine sahipse en iyi alternatiftir. $\mathrm{Bu}$ nedenle alternatiflerin öncelik siralaması $r_{\mathrm{oi}}$ değerinin büyükten küçüğe doğru sıralanması ile elde edilir.

\subsection{DEMATEL (The Decision Making Trial and Evaluation Laboratory Method)}

DEMATEL, kriterler arasındaki sebep-sonuç ilişkilerini kapsayan yapısal bir model oluşturmak ve analiz etmek için kullanılan kapsamlı bir yöntemdir [54]. 1972 ve 1976 yılları arasında Cenevre Battelle Memorial Enstitüsü Bilim ve İnsan İşleri Programı tarafindan geliştirilen DEMATEL bir grup karmaşık ve iç içe problemleri çözmek için kullanılmıştır [5556]. Aksakal ve Dağdeviren' in çalışmasında, kriter ilişki değerlerinden bağımlı ağırlıklarının elde edilmesi 5 adımdan oluşmaktadır [57]:

Adım 1: Direkt ilişki matrisinin oluşturulması

Örnekte n kriter için $H$ uzmanının her birine i kriterin j kriterini hangi derecede etkilediği sorulmuştur. Her iki kriterin ikili karşılaştırması 0 ile 4 aralığında $x_{i j}{ }^{k}$ ile gösterilen bir değer almaktadır. "(0) etkisiz”, “(1) düşük etkili”, “(2) orta etkili”, “(3) yüksek etkili” ve "(4) çok yüksek etkili” [58]. Her uzmandan alınan $k=1,2, \ldots, H n x n$ boyutundaki matrislerin ortalamas alınarak $A=\left[a_{i j}\right]_{n x n}$ direkt ilişki matrisi elde edilir.

$a_{i j}=\frac{1}{H} \sum_{k=1}^{H} x_{i j}^{k}$

Adım 2: Normalleştirilmiş direkt ilişki matrisinin oluşturulması

Sütundaki en küçük değer $t$ değeri kullanılarak denklem (13) ve (14) ile normalleştirilmiş direkt ilişki matrisi $M$ elde edilir. 
$t=\operatorname{Min}\left(\frac{1}{\max _{1 \leq i \leq n} \sum_{j=1}^{n}\left|a_{i j}\right|}, \frac{1}{\max _{1 \leq j \leq n} \sum_{j=1}^{n}\left|a_{i j}\right|}\right)$

$M=t x A$

Adım 3: Toplam direkt ilişki matrisinin oluşturulması Toplam ilişki matrisi I normalleştirilmiş ilişki matrisi $S$ ' den aşağıdaki eşitlikle elde edilir.

$$
\begin{aligned}
& S=M+M^{2}+M^{3}+\cdots=\sum_{i=1}^{\infty \leftarrow} M^{i} \\
& =M(1-M)^{-1}
\end{aligned}
$$

Adım 4: Toplam direkt ilişki matrisi $S^{\prime}$ den satır toplamı $R$ ve sütun toplamı $D$ ' nin oluşturulması

$$
\begin{aligned}
& R=\left[R X R r_{i}\right]_{n x 1}=\left[R X R \sum_{j=1}^{n} s_{i j}\right]_{n x 1} \\
& D=\left[R X R d_{j}\right]_{1 x n}=\left[R X R \sum_{i=1}^{n} s_{i j}\right]_{1 x n}
\end{aligned}
$$

$\mathrm{D}+\mathrm{R}$ değeri her bir kriterin diğer kriterle arasındaki ilişkiyi ve D-R ise kriterin sisteme net etkisini gösterir.

Adım 5: Son olarak etki diyagramını çizebilmek için bir eşik değer tanımlanır.

DEMATEL' in bu adımlarına ek olarak SMAADEMATEL-GİA algoritmasında kullandığımız kriter ağırlıkları matrisini elde etmek için aşağıdaki adım uygulanır.

\section{Adım 6: Kriter ağırlıkları matrisi}

Uzmanlar tarafindan belirlenen eşik değere göre kriter ağırlıkları matrisi elde edilir. Bu matris kriterlerin ağırlıkları ile çarpılarak kriterlerin bağımlı ağırlıkları elde edilmiş olur.

\subsection{SMAA-2 Yöntemi ( SMAA-2 Method)}

SMAA Lahdelma tarafindan 1998 yılında çok kriterli karar destek tekniği olarak önerilmiştir $[6,11]$. Bu yöntem kesin veya geçerli olmayan, eksik veriler olduğunda (örneğin: ağırlıklar, kriter değerleri) karar vericinin kesin tercihlerine ihtiyaç duymadan karar vermesine yardımcı olan bir yöntemdir. Popüler ÇKKV yöntemlerinden farklı olarak SMAA' ların amacı en iyi alternatifi bulmak değil o alternatifi destekleyen farklı değerlendirmeleri elde edebilmektedir.

Lahdelma ve Salminen (2001) SMAA-2 yöntemi ile birçok farklı tercih bilgisini kullanmaya uygun ve bütün sıralamaları bütünsel olarak dikkatte alabilen genel fayda fonksiyonunu genelleştirmiştir [11].

Karar problemi n kriter $\left\{g_{l}, \ldots, g_{j}, \ldots, g_{n}\right\}, m$ alternatif $A=\left\{x_{1}, x_{2} \ldots ., x_{m}\right\}$ ve bir grup karar vericiden oluşmaktadır. $x_{i}$ alternatifinin $g_{\mathrm{j}}$ kriterine göre değerlendirilmesi $g_{j}\left(x_{i}\right)$ ile gösterilir.

Karar vericilerin tercih bilgisi fayda fonksiyonu $u\left(x_{i}, w\right)$ ile gösterilir. $\mathrm{Bu}$ fonksiyon ağırlıklarla atanan farklı alternatiflerin her bir karar verici için tercini belirler.

$u\left(x_{i}, w\right)=\sum_{j=1}^{n} w_{j} g_{j}\left(x_{i}\right)$

Ağırlıkların negatif olmadığı ve normalize edilmiş olduğu varsayılır. Bu durumda uygun ağırlıklar kümesi aşağıdaki gibi tanımlanır:

$W=\left\{w \in R^{n}: w \geq 0\right.$ ve $\left.\sum_{j=1}^{n} w_{j}=1\right\}$

Kesin olmayan ve belirsiz kriter değerleri stokastik değişken $\xi_{i j}$ ile ve $X$ uzayındaki olasılık dağılımlı yoğunluk fonksiyonu da $f(\xi)$ ile ifade edilir. Karar vericilerin bilinmeyen veya k1smen bilinen tercihlerini ağırlık uzayında $W: f(w)=1 / \operatorname{vol}(w)$ yoğunluk fonksiyonu $f(w)$ ile birlikte ağırlık dağılımı ile gösterilir.

Değer dağılımına göre en iyi alternatiften $(=1)$ en kötü alternatife $(=m)$ kadar her bir alternatif sıralama fonksiyonu ile siralanır.

$\operatorname{rank}(i, \xi, w)=1+\sum_{k \neq i} \rho\left(u\left(\xi_{k}, w\right)>u\left(\xi_{i}, w\right)\right)$

$\rho\left(\right.$ doğru) ise 1 ve $\rho($ yanlış $)$ ise $0^{\prime}$ dır.

SMAA-2 stokastik kümelerinin analizinde destekleyici sıra ağırlıklarını temel alır:

$$
W_{i}^{r}(\xi)=\{w \in W: \operatorname{rank}(i, \xi, w)=r\}
$$

Önceki tanımda da belirtildiği üzere SMAA-2 yöntemi üç ölçüm kullanır: sıra kabul edilebilirlik indisleri, merkezi ağırlık vektörleri ve güvenilirlik faktörleri. Sıra kabul edilebilirlik indisi, bir alternatifin o sirada olmasını farklı tercihlerin sonucu olarak ölçer [59]. Bu parametre kriter dağılımları ve destekleyici sıra ağırlıklar kümesi üzerinde çok boyutlu integrallerle hesaplanır.

$$
b_{i}^{r}=\int_{\xi \in x} f_{x}(\xi) \int_{w \in W_{i}^{r}(\xi)} f_{w}(w) d w d \xi
$$

Yüksek sıra kabul edilebilirlik indisi daha iyi sıralama ve daha iyi alternatif anlamına gelir. Sira kabul edilebilirlik indisleri [ $\left.\begin{array}{ll}0 & 1\end{array}\right]$ aralığında yer alır, " 0 " o alternatifin o sırada hiçbir zaman yer alamayacağını, " 1 " ise o alternatifin hangi ağırlıklar olursa olsun o sırada yer alacağını gösterir. İlk sıra kabul edilebilirlik indisi kabul edilebilirlik indisi $\mathrm{a}_{\mathrm{i}}{ }^{6}$ dir. Kabul edilebilirlik indisi stokastik olarak etkin alternatifler için " 0 "dan farklı bir değer alırken etkin olmayan 
alternatifler için " 0 ” değerini alır. Kabul edilebilirlik indisi sadece etkin alternatifleri incelemez ayrica kriter ve karar vericinin tercihlerindeki belirsizlikleri de dikkate alarak etkinlik derecesini de ölçer. İki kriterli, üç alternatifli ve doğrusal fayda fonksiyonlu deterministik problemin destekleyici sıra ağırlıkları ve sıra kabul edilebilirlik indisleri grafiksel olarak Şekil 1' de gösterilmiştir. Destekleyici ilk sıra ağırlıkları açık gri, ikinci sıra ağırlıkları koyu gri ile gösterilmiştir.

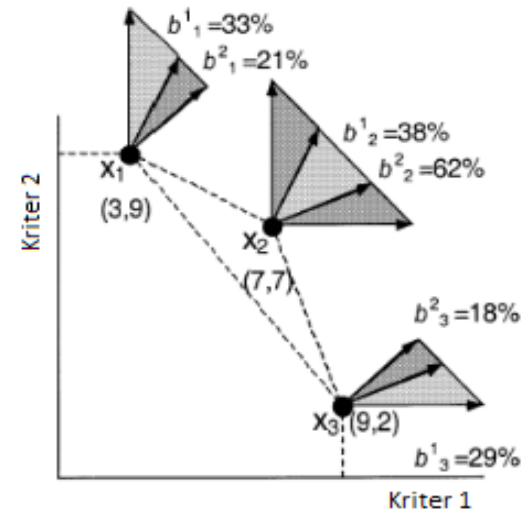

Şekil 1. İki kriterli doğrusal fayda fonksiyonlu problemin destekleyici sıra ağırlıkları ve sıra kabul edilebilirlik indisleri (Favorable weights and acceptability indices in the deterministic 2 criteria case with linear utility function) [11].

Merkezi ağırlık vektörü $\mathrm{w}_{\mathrm{i}}^{\mathrm{c}}$ ise bir alternatifin destekleyici birinci sıra ağırlığının beklenen ağırlık merkezidir. $\mathrm{Bu}$ kriter dağılımları ve destekleyici birinci sıra ağırlıkları üzerinde çok boyutlu integrallerle hesaplanır.

$w_{i}^{c}=\frac{1}{a_{i}} \int_{\xi \in x} f_{x}(\xi) \int_{w \in W_{i}(\xi)} f_{w}(w) w d w d \xi$

Merkezi ağırlık vektörü varsayılan tercih modeli ile bu alternatifi destekleyen karar vericinin tercihlerini tanımlar. Karar verici merkezi ağırlık vektörlerinden varsayılan tercih modelindeki farklı tercihleri farklı alternatiflerin nasıl farklı ağırlıklarla sağladığını gösterir. Güvenilirlik faktörü, $\mathrm{p}_{i}{ }^{\mathrm{c}}$, bir alternatifin onun merkezi ağırlık vektörü seçildiğinde birinci sırayı elde etme olasılığıdır. Kriter dağılımları üzerinde çok boyutlu integrallerle hesaplanır [11].

$$
p_{i}^{c}=\int_{\substack{\xi \in X: u\left(\xi_{i}, w_{i}^{c}\right) \geq u\left(\xi_{k}, w_{i}^{c}\right) \\ \forall k=1, \ldots \ldots, m}} f_{x}(\xi) d \xi
$$

Güvenilirlik faktörü etkin alternatifleri ayırt etmek için ölçümlerin yeteri kadar geçerli olup olmadığını gösterir. Eğer problem formülasyonu bir alternatifi seçerse, düşük güvenilirlik faktörü o alternatifin en iyi olarak seçilmesinin güvenilir olamayacağını gösterir. Daha güvenilir karar verebilmek için daha geçerli kriter verileri toplanmalıdır [18]. Belirsiz kriter değerleri ve kısmen eksik tercih bilgisinin esnek ve detaylı modellemesi için SMAA formülasyonları kullanılabilir ve çok boyutlu integrallerin hesaplamasında sayısal teknik olarak genelde Monte Carlo simülasyonu kullanılır [11].

\section{3. ÖNERİLEN YÖNTEMLER (PROPOSED METHODS)}

SMAA' nın daha önce karar verme yöntemlerinden özellikle ELECTRE [16, 12], PROMETHE [33] ve TOPSIS [17] yöntemleri ile başarıyla uygulanmış entegrasyonları olsa da literatürde GİA ile uygulanmasına rastlanılamamıștır. Hiç biri birbirinden daha üstün olamayan ve her biri karar vericiye farklı bakış açısı kazandıran ÇKKV' nin her bir yöntemi, literatürde farklı uygulamalarda, karar vermede etkin olarak kullanılmaktadır. Bu çalışmada, SMAA ile GİA ve DEMATEL yöntemlerinin kombinasyonu, iki yeni yöntem SMAA-GİA ve SMAA-DEMATEL-GİA önerilmiştir. SMAA' nın DEMATEL ile birlikte uygulamasını Eroğlu (2014) tezinde sunmuştur [60]. $\mathrm{Bu}$ tezde DEMATEL, SMAA ile entegre şekilde kullanılmayıp, SMAA-2 modelinin ağırlıkları, DEMATEL ile elde edilen önem sirasında rasgele kullanması sağlanmıştır. Önerilen SMAADEMATEL-GİA yönteminde SMAA' nın ağırlıkları rasgele elde etmesine müdahale edilmeden Aksakal ve Dağdeviren [57]' in çalışmasında uyguladıkları gibi kriter ilişki değerleri ile bağımlı ağırlıklar elde edilip kriterler arası bağımlılıkların karar verme sürecine dahil edilmesi sağlanmıștır. Literatürde, SMAA-2 yönteminin belirsiz ve bağımlı verilerle başa çıkabilmesi için de çalışmalar yapılmıştır. Lahdelma v.d. (2006) beklenen değer, standart sapma ve bağımlılık bilgisini içeren korelasyon matrisini kullanan Çok Değişkenli Gauss Dağılımını uygulamıştır [61]. Kangas v.d. (2006) orman planlamasında kriterler arası ilişkileri Çok Değişkenli Gauss Dağılımı ile karar mekanizmasına katılmasını sağlamışlardır [20]. Lahdelma v.d. (2009) çalışmalarında stokastik çok kriterli karar vermede bağıml belirsizlikler için iki yöntemden bahsetmişlerdir [62]. Bunlardan ilki bağımlılık bilgilerini temsil etmek için dağılım örneğini doğrudan SMAA-2' de uygulamak, ikincisi ise örnekte Çok Değişkenli Gauss dağılımını kullanmaktır. Her iki yöntemde alternatifler arası korelasyonun çok olduğu örnekte uygulanmış ve sonuçlar önemli ölçüde iyileştirilmiştir. Ancak önerilen yöntemlerden ilki çok sayıda örneklem olduğunda uygulanabilmektedir. İkincisinde ise Çok değişkenli Gauss dağılımının uygulanmasındaki anlamlılık, stokastik kriterlerin bu dağılıma ne kadar uyduğu ile doğrudan ilişkilidir. Verilerin çok değişkenli normalliğini test etmek mümkündür. Ancak, bu tür testler oldukça karmaşıktır ve güvenilir sonuçlar için oldukça büyük bir örnek gerektirir ayrıca da her zaman gerçek hayat karar verme durumlarında geçerli olmayabilir [62]. Bu yöntemlerin uygulanamadığ 
daha az matematiksel hesaplama ve işlemler sırasında daha az eleman gerektiren DEMATEL yöntemi, kullanılabilitesi yüksek, basit, esnek, kullanıcı dostu alternatif bir yaklaşım olarak SMAA ile entegre edilmiştir.

\section{1 Önerilen Yöntem: SMAA-GİA (The Proposed Method: SMAA-GRA)}

GİA; bir derecelendirme, sinıflama ve karar verme tekniği olarak kısıtlı ve az sayıda veri seti ile birlikte bir sistem için gerekli faktörlerin önemli olanlarını bulmak için kullanılabilmektedir. GİA, kriterler arasında ilişkilerin belirsiz olduğu veya değişkenler arasında belirsiz ilişkiler söz konusu olduğunda veya bir değişkenin, sistemin bütünü üzerindeki etkisi belirsiz olduğunda kullanılır [63]. GİA ilişki analizinde, seriler arasındaki ilişkiyi daha az veri ile açıklamaya çalışılır. $\mathrm{Bu}$ avantajıyla birlikte istatistiksel yöntemlerin dezavantajları elenmiş olmaktadır [46]. Bununla birlikte GİA' nın diğer ÇKKV yöntemleri ile birlikte karşılaştırmalı uygulamasında, sonuçlar diğer yöntemlerle yakın çıkmıştır [64]. Tüm bu avantajları göz önüne alındığında çok kriterli karar vermede önemli bir yöntem olan GİA bu çalışmada tercih edilmiştir. SMAA-2' nin GİA ile entegrasyonu, GİA' nın belirsiz ve kesin olmayan verilerde kullanımını SMAA-2'nin de göreceli önemi değerlendirebilmesini sağlamıştır. SMAA-GİA yönteminde fayda fonksiyonunu hesaplamak için MATLAB yardımıyla program kodu hazırlayarak SMAA-2'nin orijinal fayda fonksiyonu ile GİA algoritması yer değiştirilmiştir. SMAA-GİA prosedürü akış şeması Şekil 2'de gösterilmiştir. SMAA-GİA yöntemi Monte Carlo simülasyonu hesaplamalarını kullanır. Her bir simülasyon iterasyonu için belirsiz kriter değerleri ve ağırlıklar kendi dağılımından oluşturulur. Her bir iterasyon için bu değerlerle GİA yöntemi çalıştırıldıktan sonra optimum çözüm için alternatiflerin göreli yakınlıkları elde edilir. Yeterli sayıda iterasyondan sonra simülasyon sürecindeki değerlerin analizi ile sıra kabul edilebilirlik indisi, merkezi ağırlık vektörü ve güvenilirlik faktörleri elde edilir.

SMAA-GİA’ nın adımları aşağıdaki gibidir:

Adım 1: Kriter dağılımları ve ağırlık ölçüleri belirlenir. SMAA-2 yönteminde de olduğu gibi SMAA-GİA yönteminde de hem kriterler hem de ağırlıklar yoğunluk fonksiyonu ile belirtilir. $\mathrm{Bu}$ adımda yoğunluk fonksiyonlarına karar verilir.

Adım 2: Belirlenen dağılımlara uygun parametre değerleri oluşturulur. Bir önceki bölümde belirlenen dağılıma göre dağılım parametreleri elde edilir. Bu makaledeki çalışmalarda normal dağılım uygulanmıştır ve normal dağılımın parametresi olan alternatiflerin her bir kriter için hem ortalama hem de standart sapma değerleri elde edilir. SMAA-GİA yönteminde Gİ' nın girdisi olan deterministik değerleri yoğunluk fonksiyonlarından elde etmek için integrallerin hesaplamasında Monte Carlo simülasyonu uygulanmıştır. Her bir iterasyonda farklı belirsiz kriter verileri ve ağırlık değerleri kendi dağılımlarından elde edilir.

Adım 3: GİA algoritmasının çalıştırılması. Her iterasyonda bir önceki adımda elde edilen verilerle GİA algoritması çalıştırılır. GİA' nın çıktısı olarak alternatiflerin öncelik sırlaması $\mathrm{r}_{\mathrm{oi}}$ elde edilir.

Adım 4: Her işlem sonucu sıralamanın güncellenmesi. GİA' nın sonuçlarına göre alternatifler siraları elde edilir.

Adım 5: Sıra kabul edilebilirlik indisi, merkezi ağırlık vektörü ve güvenilirlik faktörlerinin hesaplanması. Yeterli sayıda iterasyondan sonra sira kabul edilebilirlik indisi, merkezi ağırlık vektörü ve güvenilirlik faktörü değerleri elde edilir.

Adım 6: Kararın oluşturulması. Alternatifler sıra kabul edilebilirlik indisi değerlerine göre değerlendirilir. Yüksek sira kabul edilebilirlik indisi değerine sahip olması daha iyi alternatif olduğunu gösterir.

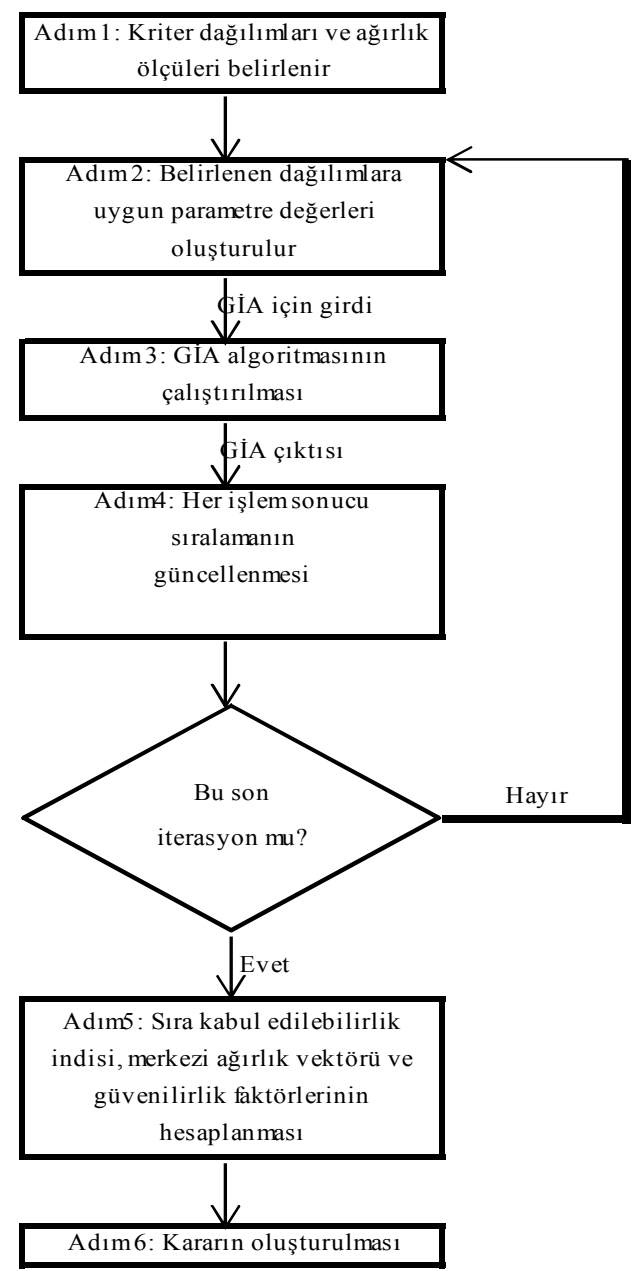

Şekil 2. SMAA-GİA Akış Şeması (Flow chart of SMAAGRA) 


\section{2 Önerilen Yöntem: SMAA-DEMATEL-GİA (The Proposed Method: SMAA-DEMATEL-GRA)}

Kriterlerin etkileşimin olduğu karar verme probleminde uygulanmak üzere SMAA-DEMATELGİA yöntemi önerilmiştir. SMAA-GİA yöntemine DEMATEL yöntemi de entegre edilerek SMAADEMATEL-GİA ile kriterlerin birbirlerine olan etkisi stokastik verilerle karar verme sürecine eklenmiştir. DEMATEL yöntemi daha önce Aksakal ve Dağdeviren' in çalışmasında kriterlerin bağımlı ağırlıklarını elde etmek için kullanılmıştır [57]. Yapılan çalışmada, bu çalışma referans alınarak kriterlerin bağımlı ağırlıkları elde edilmiştir. SMAA-2 algoritması ile elde edilen rasgele ağırlık değerleri DEMATEL' den elde edilen kriterlerin ağırlık matrisi ile çarpılarak kriterlerin bağımlı ağırlıkları elde edilmiştir. Her iterasyonda rasgele ağırlıklar değişmekte ancak kriterlerin birbirlerine olan etkisi göz ardı edilmemektedir.

SMAA-DEMATEL-GİA algoritmasıyla, SMAA-GİA ile elde edilen avantajlara ek olarak karar vericilerin, kriterlerin bağımlı ağırlıklarını karar verme sürecinde kullanmaları sağlanmıştır.

SMAA-DEMATEL-GİA yönteminde hem fayda fonksiyonunu hesaplamak hem de bağımlı kriter ağırlıklarını belirlemek için MATLAB yardımıyla program kodu hazırlanmıştır. SMAA-DEMATELGİA yöntemi de Monte Carlo simülasyonu hesaplamalarını kullanır. Her bir simülasyon /iterasyonda kriter ve ağırlık değerlerinin yanı sıra DEMATEL' in girdisi olan olasılık yoğunluk fonksiyonu ile belirtilen kriterlerin direkt ilişki matrisi değerleri de kendi dağılımlarından elde edilir. Şekil 3'de akış şeması gösterilmiş olan SMAADEMATEL-GİA prosedürünün adımları aşağıdaki şekilde özetlenebilir:

Adım 1: Kriter dağılımları ve ağırlık ölçüleri belirlenirken SMAA-GİA' ya ek olarak kriterlerin direkt ilişki matrisi değerlerinin de dağılımı belirlenir.

Adım 2: Belirlenen dağılımlara uygun parametre değerlerini oluşturulur. Bu adımda DEMATEL' in girdisi olan direkt ilişki matrisi değerleri de oluşturulur.

Adım DEMATEL: Kriterlerin Bağımlı Ağırlıklarının Belirlenmesi. Bir önceki adımda elde edilen verilerle DEMATEL algoritması çalıştırılır. DEMATEL' den elde edilen "kriter ağırlıkları matrisi" ile SMAA'dan elde edilen kriter ağırlık değerleri çarpılarak "kriterlerin bağımlı ağırlık değerleri” elde edilir.

Adım 3: GİA algoritmasının çalıştırılması. Her iterasyonda Adım 2'den elde edilen kriter değerleri ve Adım DEMATEL' den elde edilen ağırlık bilgisi ile İA algoritması çalıştırılır. GİA' nın çıktısı olarak alternatiflerin öncelik sıralaması $r_{o i}$ elde edilir. Adım 4, 5 ve 6 SMAA-GİA ile aynı şekilde çalışmaktadır.

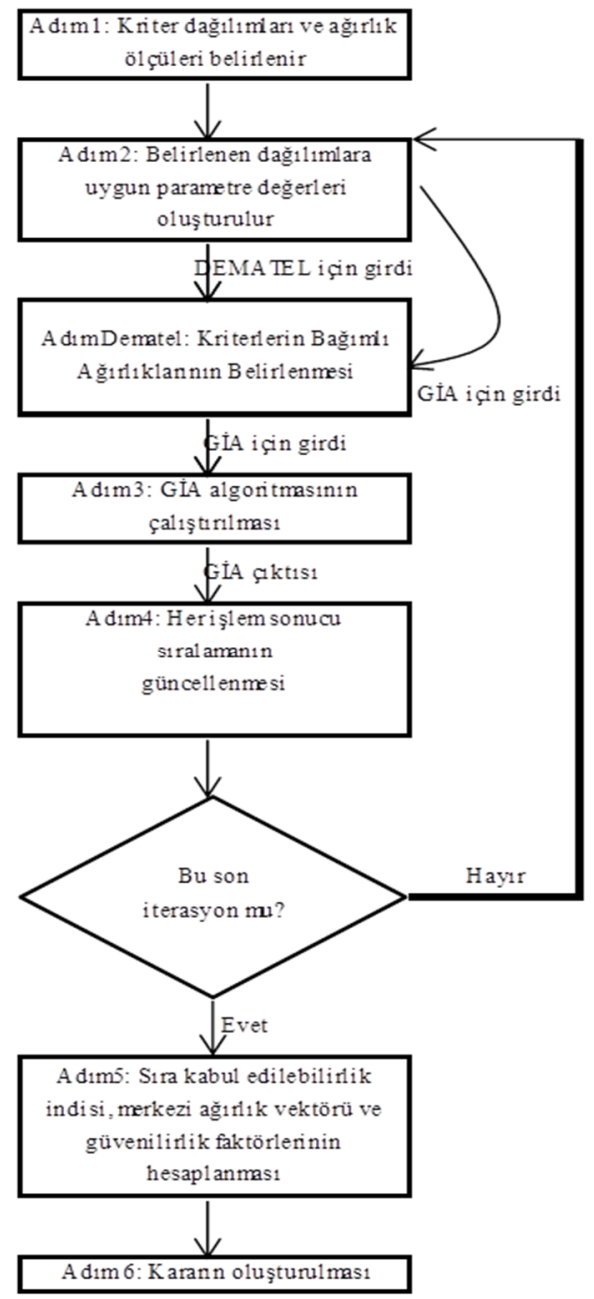

Şekil 3. SMAA-DEMATEL-GİA Akış Şeması (Flow chart of SMAA-DEMATEL-GRA)

\section{SMAA-2 \& SMAA-GIA \& SMAA-DEMATEL- GİA YÖNTEMLERININ KARŞILAŞTIRILMASI (COMPARING THE METHODS: SMAA-2 \& SMAA-GRA \& SMAA-DEMATEL-GRA)}

SMAA, SMAA-GİA ve SMAA-DEMATEL-GİA yöntemleri bir literatür problemi, ilaç fayda risk analizine ve gerçek hayat uygulaması olarak da Türk havacılık şirketleri performansı değerlendirmesine uygulanmış ve sonuçlar değerlendirilmiştir. Bütün modeller, hiçbir sıralama bilgisi olmadan normal dağılıma sahip verilerle çözülmüş ve hesaplamalar 10.000 Monte Carlo simülasyonu ile gerçekleştirilmiştir. Ayrıca SMAA ve SMAA-GİA çözümlerinde kriterlerin birbirinden bağımsız olduğu varsayılmıştır.

\section{1 İlaç Fayda Risk Analizi (Drug Benefit-Risk Analysis)}

Tervonen ve diğg. (2010) ilaç fayda risk analizi üzerine yaptıkları çalışmalarında Fluoxetine, Paroxetine, Sertraline ve Venlafaxine isimli dört antidepresan1, biri fayda ve beşi yan etki kriterlerine göre SMAA yöntemi ile analiz etmişlerdir [38]. Tablo 1' deki 
Ternoven v.d. [38]'nin ilaç fayda risk analizi verilerine, SMAA-GİA ve SMAA-DEMATEL-GİA yöntemleri de uygulanmıştır. SMAA-DEMATELGİA uygulamasinda ise, Tablo 1'deki verilere ek olarak, farmakoloji uzmanları ile yapılan yüz yüze görüşmelerden elde edilen, Tablo 2'deki kriterler arası etki matrisi de kullanılmış ve elde edilen sonuçlar SMAA ile karşılaştırılmıştır. Elde edilen sıra kabul edilebilirlik indisi, Tablo 3'te ve merkezi ağırlık vektörleri ile güvenilirlik faktörleri de Tablo 4'te listelenmiştir.

Tablo 1. Kriter Ölçekleri (Değerler Ortalama ve Std. sapma şeklindedir.) (Criteria measurements. The values are given as mean \pm standard deviation) [38]

\begin{tabular}{|c|c|c|c|c|c|c|}
\hline İlaç & 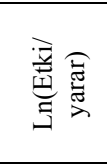 & 馬 & 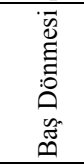 & 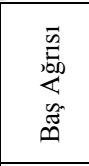 & 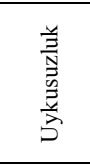 & 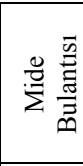 \\
\hline Fluoxetine & $0 \pm 0$ & $\begin{array}{l}11,7 \pm \\
2,5\end{array}$ & $\begin{array}{l}7,2 \pm \\
1,45\end{array}$ & $\begin{array}{l}16,6 \pm \\
3,27\end{array}$ & $\begin{array}{l}13,7 \pm \\
1,89\end{array}$ & $\begin{array}{l}18,6 \pm \\
1,79\end{array}$ \\
\hline Paroxetine & $\begin{array}{l}0,086 \pm \\
0,056\end{array}$ & $\begin{array}{l}9,2 \pm \\
1,86\end{array}$ & $\begin{array}{l}10,6 \pm \\
1,58\end{array}$ & $\begin{array}{l}21,2 \pm \\
5,15\end{array}$ & $\begin{array}{l}14,3 \pm \\
2,93\end{array}$ & $\begin{array}{l}18,3 \pm \\
3,7\end{array}$ \\
\hline Sertraline & $\begin{array}{l}0,095 \pm \\
0,044\end{array}$ & $\begin{array}{l}15,4 \pm \\
2,65\end{array}$ & $\begin{array}{l}7,5 \pm \\
1,48\end{array}$ & $\begin{array}{l}20,2 \pm \\
3,78\end{array}$ & $\begin{array}{l}15 \pm \\
3,21\end{array}$ & $\begin{array}{l}19,5 \pm \\
2,6\end{array}$ \\
\hline Venlafaxine & $\begin{array}{l}0,113 \pm \\
0,048\end{array}$ & $\begin{array}{l}5,5 \pm \\
2,32\end{array}$ & $\begin{array}{l}15,7 \pm \\
4,44\end{array}$ & $\begin{array}{l}12,8 \pm \\
2,45\end{array}$ & $\begin{array}{l}11,2 \pm \\
3,98\end{array}$ & $\begin{array}{l}31 \pm \\
1,68\end{array}$ \\
\hline
\end{tabular}

Tablo 2. Kriterlerin direkt-ilişki matrisi (Değerler Ortalama ve Std. sapma şeklindedir.) (Direct-relation matrix of criteria The values are given as mean \pm standard deviation)

\begin{tabular}{|c|c|c|c|c|c|c|}
\hline İlaç & 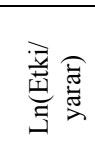 & 馬 & 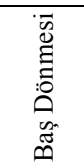 & 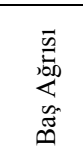 & 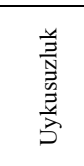 & 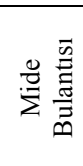 \\
\hline Fluoxetine & $0 \pm 0$ & $\begin{array}{l}11,7 \pm \\
2,5\end{array}$ & $\begin{array}{l}7,2 \pm \\
1,45\end{array}$ & $\begin{array}{l}16,6 \pm \\
3,27\end{array}$ & $\begin{array}{l}13,7 \pm \\
1,89\end{array}$ & $\begin{array}{l}18,6 \pm \\
1,79\end{array}$ \\
\hline Paroxetine & $\begin{array}{l}0,086 \pm \\
0,056\end{array}$ & $\begin{array}{l}9,2 \pm \\
1,86\end{array}$ & $\begin{array}{l}10,6 \pm \\
1,58\end{array}$ & $\begin{array}{l}21,2 \pm \\
5,15\end{array}$ & $\begin{array}{l}14,3 \pm \\
2,93\end{array}$ & $\begin{array}{l}18,3 \pm \\
3,7\end{array}$ \\
\hline Sertraline & $\begin{array}{l}0,095 \pm \\
0,044\end{array}$ & $\begin{array}{l}15,4 \pm \\
2,65\end{array}$ & $\begin{array}{l}7,5 \pm \\
1,48\end{array}$ & $\begin{array}{l}20,2 \pm \\
3,78\end{array}$ & $\begin{array}{l}15 \pm \\
3,21\end{array}$ & $\begin{array}{l}19,5 \pm \\
2,6\end{array}$ \\
\hline Venlafaxine & $\begin{array}{l}0,113 \pm \\
0,048\end{array}$ & $\begin{array}{l}5,5 \pm \\
2,32\end{array}$ & $\begin{array}{l}15,7 \pm \\
4,44\end{array}$ & $\begin{array}{l}12,8 \pm \\
2,45\end{array}$ & $\begin{array}{l}11,2 \pm \\
3,98\end{array}$ & $\begin{array}{l}31 \pm \\
1,68\end{array}$ \\
\hline
\end{tabular}

Bütün modellerin sonuçları incelendiğinde, SMAAGİA ile elde edilen sira kabul edilebilirlik indis değerleri SMAA ile yakın, ancak daha net sıralama sonucu vermektedir. Tablo 4 incelendiğinde SMAA' da Venlafaxine' nin güvenilirlik faktörü 0,74 iken; SMAA-GİA' da bu değer 0,80'e yükselmiştir. SMAAGİA sonuçlarında Venlafaxine' in merkezi ağırlık vektörlerine bakıldığında, ishal yan etkisi \%21 'lik oranla en yüksek göreli öneme sahiptir. Sırasıyla baş ağrısı \%20, uykusuzluk \%18, yarar/etki \%18, baş dönmesi $\% 12$, mide bulantısı \%11merkezi ağırlı k vektör değeriyle göreli öneme sahip olmuştur.
Tablo 3. Sira kabul edilebilirlik indisi (Rank acceptability indices)

\begin{tabular}{|c|c|c|c|c|}
\hline \multicolumn{5}{|c|}{$S M A A$} \\
\hline İlaç & Sira 1 & Sira 2 & Sira 3 & Sira 4 \\
\hline Fluoxetine & 0,2 & 0,28 & $\underline{0,3}$ & 0,22 \\
\hline Paroxetine & 0,25 & $\underline{0,29}$ & 0,27 & 0,19 \\
\hline Sertraline & 0,17 & 0,25 & 0,29 & 0,29 \\
\hline Venlafaxine & $\underline{0,38}$ & 0,18 & 0,14 & $\underline{0,3}$ \\
\hline \multicolumn{5}{|c|}{$S M A A-G \dot{I} A$} \\
\hline İlaç & Sira 1 & Sira 2 & Sira 3 & Sira 4 \\
\hline Fluoxetine & 0,196 & $\underline{0,288}$ & 0,287 & 0,223 \\
\hline Paroxetine & 0,167 & 0,259 & $\underline{0,293}$ & 0,288 \\
\hline Sertraline & 0,157 & 0,252 & 0,274 & $\underline{0,316}$ \\
\hline Venlafaxine & $\underline{0,481}$ & 0,201 & 0,147 & 0,172 \\
\hline \multicolumn{5}{|c|}{$S M A A-D E M A T E L-G \dot{I} A$} \\
\hline İlaç & Sira 1 & Sira 2 & Sira 3 & Sira 4 \\
\hline Fluoxetine & 0,1980 & 0,2977 & 0,2868 & 0,2175 \\
\hline Paroxetine & 0,1704 & 0,2593 & 0,2827 & 0,2876 \\
\hline Sertraline & 0,1600 & 0,2370 & 0,2806 & 0,3224 \\
\hline Venlafaxine & 0,4716 & 0,2060 & 0,1499 & 0,1725 \\
\hline
\end{tabular}

Hem SMAA hem de SMAA-GİA yöntemleri Venlafaxine' i en iyi alternatif olarak seçmiştir. Ancak SMAA sonuçlarina göre Venlafaxine alternatifi hem ilk hem de son sira kabul edilebilirlik indis değerlerinde en yüksek değeri alması, tercih yapacak olan karar vericiyi zorlayabilecek ve çelişkiye düşürebilecek bir sonuçtur. Bir alternatifin hem ilk hem de son sırada seçilme olasılığının diğer alternatiflere göre en yüksek değer alması bir çelişkidir. Ancak SMAA-GIA ile sıralama net bir şekilde elde edilebilmiştir. Venlafaxine $>$ Fluoxetine $>$ Paroxetine $>$ Sertraline. SMAA-DEMATEL-GİA ile, kriterler arası etkileşim de Tablo 2'deki direkt ilişki matrisindeki değerler ile modelin çözümüne eklenmiştir. Örneğin "İshal" yan etkisi "Baş dönmesi" yan etkisini 3 değeri ile yüksek etkilediğini göstermektedir. $\mathrm{Bu}$ durumda iki kriter açısından birbirini etkileme durumu göz önüne alınarak, kriter ağırlıklarının karar verme sürecine dahil edilmesi amaçlanmıştır. SMAA-DEMATEL-GİA ile SMAAGİA sonuçları karşılaştırıldığında, sıralamalar arasında fark olmadığı, ancak sonuçların SMAADEMATEL-GİA' da daha güvenilir olduğu görülmektedir. Kriterler arası etkileşimin az olması, sonuçların birbirine daha yakın çıkmasına ve sıralamaların aynı olmasına neden olmaktadır. Bu karşılaştırmalara ek olarak bu veriler GİA ile de çalıştırılmış ve sonuçlar SMAA-GİA ile karşılaştırılmıştır. Kriter ölçülerin ortalaması kesin veri olarak kabul edilmiş ve kriter ağırlıkları da SMAA-GİA yönteminde elde edilen ortalama ağırlıkları kullanılmıştır. 
Tablo 4. Güvenilirlik Faktörleri ve Merkezi Ağırlık Vektörleri (Central weight vectors and confidence factors)

\begin{tabular}{|c|c|c|c|c|c|c|c|}
\hline \multicolumn{8}{|c|}{ SMAA } \\
\hline İlaç & 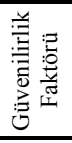 & 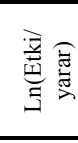 & $\overline{\underline{\pi}}$ & 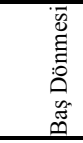 & 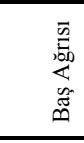 & 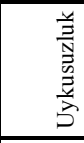 & 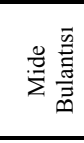 \\
\hline Fluo. & 0,49 & 0,08 & 0,14 & 0,24 & 0,18 & 0,15 & 0,21 \\
\hline Par. & 0,43 & 0,18 & 0,17 & 0,15 & 0,13 & 0,15 & 0,22 \\
\hline Sert. & 0,35 & 0,21 & 0,09 & 0,22 & 0,13 & 0,15 & 0,2 \\
\hline Venl & 0,74 & 0,19 & 0,21 & 0,12 & 0,21 & 0,18 & 0,09 \\
\hline \multicolumn{8}{|c|}{ SMAA-GİA } \\
\hline İlaç & 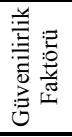 & 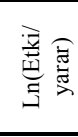 & 烝 & 离 & 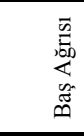 & 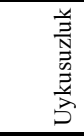 & 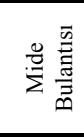 \\
\hline Fluo. & 0,43 & 0,1 & 0,12 & 0,25 & 0,16 & 0,16 & 0,22 \\
\hline Par. & 0,26 & 0,19 & 0,15 & 0,14 & 0,12 & 0,15 & 0,24 \\
\hline Sert. & 0,29 & 0,2 & 0,1 & 0,24 & 0,12 & 0,15 & 0,19 \\
\hline Venl & 0,8 & 0,18 & 0,21 & 0,12 & 0,2 & 0,18 & 0,11 \\
\hline \multicolumn{8}{|c|}{ SMAA-DEMATEL-GİA } \\
\hline İlaç & 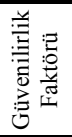 & 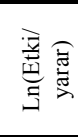 & 烝 & 离 & 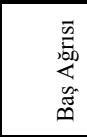 & 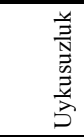 & 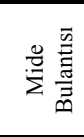 \\
\hline Fluo. & 0,43 & 0,1 & 0,13 & 0,25 & 0,17 & 0,16 & 0,22 \\
\hline Par. & 0,27 & 0,2 & 0,16 & 0,14 & 0,12 & 0,16 & 0,25 \\
\hline Sert. & 0,3 & 0,2 & 0,11 & 0,24 & 0,13 & 0,15 & 0,2 \\
\hline Venl & 0,81 & 0,18 & 0,21 & 0,12 & 0,2 & 0,19 & 0,12 \\
\hline
\end{tabular}

Tablo 5. GİA sonuçları ve Diğer Yöntemlerin Karşılaştırması (Results of GRA and Compare of Other Methods)

\begin{tabular}{|c|c|c|c|c|c|}
\hline \multirow{2}{*}{ İlaç } & \multicolumn{2}{|l|}{ : } & $\sum_{\infty}^{\infty}$ & 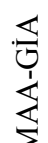 & 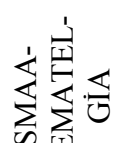 \\
\hline & $r_{o i}$ & $\frac{\overparen{\Xi}}{\frac{\pi}{\pi}}$ & 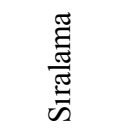 & $\frac{\widetilde{Z}}{\frac{\pi}{\pi}}$ & 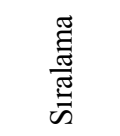 \\
\hline Fluoxetine & 0,637 & 2 & 3 & 2 & 2 veya 3 \\
\hline Paroxetine & 0,601 & 4 & 2 & 3 & \\
\hline Sertraline & 0,617 & 3 & & 4 & 4 \\
\hline Venlafaxine & 0,748 & 1 & 1 veya 4 & 1 & 1 \\
\hline
\end{tabular}

GİA' dan elde edilen gri ilişkisel analiz dereceleri ve diğer yöntemlerle elde edilen sıralamalar Tablo 5' te verilmiştir. GİA' da Venlafaxine 0,7482 ile ilk sırada yer almıştır. SMAA-GİA' da da Venlafaxine' in ilk sırada tercih edilme olasılığı da çok yüksektir. Sonuç olarak SMAA-GİA ve GİA sıralamaları birbirine çok benzerdir. Hem SMAA-GİA hem de GİA da 1. ve 2. sirada yer alan Fluoxetine ve Venlafaxine alternatiflerin sıralaması aynıdır. 3. ve 4. sırada yer alan Paroxetine ve Sertraline' in SMAA-GİA 'da sira kabul edilebilirlik indis ve GİA' da $r_{o i}$ değerleri birbirine çok yakındır. Bu alternatiflerin birbirine çok yakın olması GİA sonuçlarında sıralamanın standart sapma değerlerinin de etkisi ile SMAA-GİA' ya göre yer değiştirdiği görülmüştür.

\subsection{Türk Havacılık Şirketleri Performansının} Değerlendirilmesi (Performance Measurement Of Turkish Aviation Firms)

Havayolu taşımacılığı son yüzyılda hızla artarak günümüzde taşımacılık sektörünün önemli bir kısmını oluşturmuştur. Rekabetin yoğun olduğu sektörde doğru stratejilerin belirlenmesi karlılığı doğrudan etkiler. $\mathrm{Bu}$ bağlamda havacılık şirketlerinin performanslarının değerlendirilmesi önem kazanmaktadır. Türkiye'de farklı iş alanlarına hizmet eden birçok havacılık firması bulunmaktadır. Sadece yolcu veya kargo taşımacılığı yapan havacılık şirketleri ve kombine havacılık şirketlerinden dokuzunun performans değerlendirmesi yapılmıştır. Şirketlerin performans ölçüsü olarak kalite, itibar, etkinlik, müşteri memnuniyeti ve risk dikkate alınmıştır [65]. Karar yapısı Şekil 4'te verilmiştir.

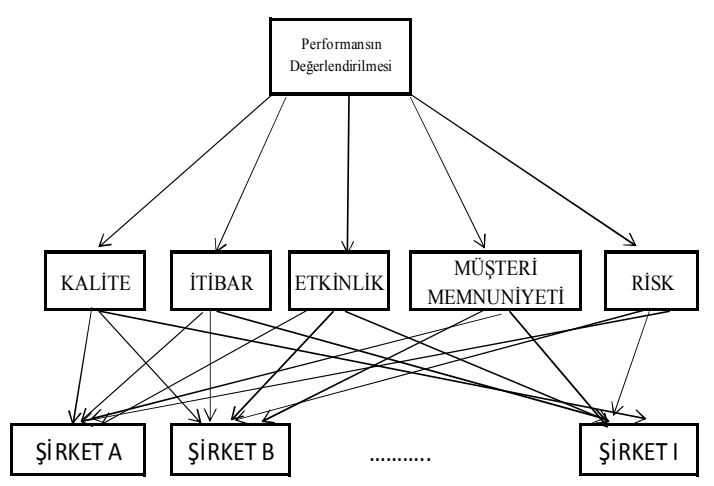

Şekil 4. Karar ağacı (Decision tree)

SMAA, SMAA-GİA, GİA ve SMAA-DEMATELGİA yöntemleri ile Türk havacılık şirketleri etkinliklerine göre karşılaştırılmıştır. Karşılaştırmada kullanılan beş kriterin biri (risk kriteri) maliyet diğer dört kriter ise fayda kriteridir. SMAA ve SMAA-GİA Tablo 6'da verilen normal dağılıma sahip verilerle çözülmüştür. SMAA-DEMATEL-GİA ise Tablo 6' deki verilere ek olarak uzmanlarla yapılan anketlerin sonucu olan Tablo 7'daki kriterlerin direkt ilişki matrisi kullanılmıştır. Havacılık sektöründe yönetici pozisyonundaki çalışanlara yapılan anket sonuçlarından Tablo 6 ve 7' deki ortalama ve standart sapma değerler elde edilmiştir. 
Tablo 6. Kriter Ölçekleri. (Değerler Ortalama ve Std. sapma şeklindedir.) (Criteria measurements. The values are given as mean \pm standard deviation)

\begin{tabular}{|c|c|c|c|c|c|}
\hline \\
\hline & KALİTE & İTİBAR & ETKİNLİK & M.MEM. & RISK \\
\hline $\mathrm{A}$ & $13,17 \pm 2,16$ & $16,3 \pm 1,8$ & $12,1 \pm 0,2$ & $9,3 \pm 3,2$ & $13 \pm 0,3$ \\
\hline B & $12,78 \pm 1,86$ & $15,9 \pm 1,6$ & $12,1 \pm 0,2$ & $14 \pm 3,2$ & $12 \pm 0,3$ \\
\hline $\mathrm{C}$ & $7,92 \pm 2,01$ & $10,4 \pm 1,6$ & $13,1 \pm 0,2$ & $9,3 \pm 3,2$ & $11 \pm 0,3$ \\
\hline D & $13,32 \pm 1,86$ & $16,3 \pm 1,6$ & $12,1 \pm 0,2$ & 3,2 & $11 \pm 0,3$ \\
\hline $\mathrm{E}$ & $18,15 \pm 1,74$ & $22 \pm 1,6$ & $11 \pm 0,2$ & $9,3 \pm 3,2$ & $12 \pm 0,3$ \\
\hline $\mathrm{F}$ & $13,47 \pm 1,89$ & $16,6 \pm 1,6$ & $12,1 \pm 0,2$ & $4,3 \pm 3,2$ & $13 \pm 0,3$ \\
\hline 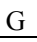 & $13,47 \pm 1,59$ & $16,4 \pm 1,4$ & $12,1 \pm 0,2$ & $9,3 \pm 3,2$ & $12 \pm 0,3$ \\
\hline 11 & $13,71 \pm 1,89$ & $16,5 \pm 1,6$ & $12,1 \pm 0,2$ & $9,3 \pm 3,2$ & $11 \pm 0,3$ \\
\hline I & $13,59 \pm 1,59$ & $16,3 \pm 1,4$ & $12,1 \pm 0,2$ & $14,8 \pm 3,2$ & $12 \pm 0,3$ \\
\hline
\end{tabular}

Tablo 7 Kriterlerin direkt-ilişki matrisi (Direct-relation matrix of criteria)

\begin{tabular}{|c|c|c|c|c|c|}
\hline & KALITE & İTIBAR & ETKINLIK & $\begin{array}{c}\text { M. } \\
\text { TATMIN }\end{array}$ & RİK \\
\hline Kalite & $0 \pm 0$ & $4 \pm 0,021$ & $3 \pm 0,021$ & $4 \pm 0,021$ & $2 \pm 0,021$ \\
\hline İtibar & $1 \pm 0,021$ & $0 \pm 0$ & $1 \pm 0,021$ & $3 \pm 0,021$ & $1 \pm 0,021$ \\
\hline Etkinlik & $4 \pm 0,021$ & $3 \pm 0,021$ & $0 \pm 0$ & $2 \pm 0,021$ & $3 \pm 0,021$ \\
\hline M. Tatmin & $1 \pm 0,021$ & $3 \pm 0,021$ & $1 \pm 0,021$ & $0 \pm 0$ & $1 \pm 0,021$ \\
\hline Risk & $3 \pm 0,021$ & $3 \pm 0,021$ & $4 \pm 0,021$ & $0 \pm 0$ & $0 \pm 0$ \\
\hline
\end{tabular}

Tablo 8. Sira kabul edilebilirlik indisi (Rank acceptability indices)

\begin{tabular}{|c|c|c|c|c|c|c|c|c|c|}
\hline \multicolumn{10}{|c|}{ SMAA } \\
\hline & 念 & $\stackrel{\sim}{\varrho}$ & $\stackrel{n}{\S}$ & む & 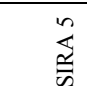 & $\begin{array}{l}0 \\
\nwarrow\end{array}$ & 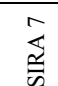 & $\stackrel{\$}{\infty}$ & 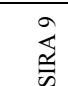 \\
\hline $\mathrm{A}$ & 0,03 & 0,13 & 0,13 & 0,12 & 0,13 & 0,14 & 0,15 & 0,18 & 0,03 \\
\hline $\mathrm{B}$ & 0,01 & 0,08 & 0,11 & 0,12 & 0,14 & 0,15 & 0,19 & 0,21 & 0,03 \\
\hline $\mathrm{C}$ & 0 & 0,01 & 0,01 & 0,01 & 0,01 & 0,01 & 0,03 & 0,08 & 0,9 \\
\hline $\mathrm{D}$ & 0,02 & 0,13 & 0,14 & 0,14 & 0,14 & 0,15 & 0,15 & 0,14 & 0,02 \\
\hline E & 0,87 & 0,1 & 0,03 & 0,01 & 0,01 & 0,01 & 0,01 & 0,01 & 0 \\
\hline $\mathrm{F}$ & 0,03 & 0,15 & 0,15 & 0,15 & 0,15 & 0,14 & 0,14 & 0,13 & 0,02 \\
\hline G & 0,02 & 0,12 & 0,15 & 0,17 & 0,17 & 0,16 & 0,14 & 0,11 & 0,01 \\
\hline $\mathrm{H}$ & 0,03 & 0,18 & 0,16 & 0,15 & 0,14 & 0,14 & 0,12 & 0,1 & 0,02 \\
\hline I & 0,02 & 0,14 & 0,17 & 0,17 & 0,16 & 0,15 & 0,12 & 0,09 & 0,01 \\
\hline \multicolumn{10}{|c|}{ SMAA-GİA } \\
\hline & 㐫 & 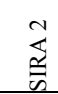 & 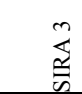 & 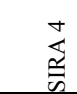 & $\begin{array}{l}n \\
\underset{n}{n}\end{array}$ & $\begin{array}{l}0 \\
\underset{\infty}{\leftrightarrows}\end{array}$ & $\stackrel{\nwarrow}{\S}$ & $\underset{\varpi}{\infty}$ & 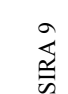 \\
\hline $\bar{A}$ & 0,01 & 0,04 & 0,05 & 0,06 & 0,08 & 0,11 & 0,16 & 0,29 & 0,25 \\
\hline B & 0,07 & 0,11 & 0,13 & 0,14 & 0,159 & 0,16 & 0,15 & 0,09 & 0,05 \\
\hline $\mathrm{C}$ & 0,26 & 0,15 & 0,12 & 0,11 & 0,09 & 0,08 & 0,08 & 0,07 & 0,1 \\
\hline $\mathrm{D}$ & 0,08 & 0,17 & 0,2 & 0,1698 & 0,14 & 0,11 & 0,08 & 0,06 & 0,03 \\
\hline$E$ & 0,42 & 0,16 & 0,11 & 0,11 & 0,08 & 0,06 & 0,05 & 0,03 & 0,03 \\
\hline $\mathrm{F}$ & 0,01 & 0,02 & 0,02 & 0,04 & 0,05 & 0,07 & 0,11 & 0,24 & 0,47 \\
\hline G & 0,01 & 0,04 & 0,06 & 0,1 & 0,15 & 0,2 & 0,24 & 0,16 & 0,07 \\
\hline $\mathrm{H}$ & 0,09 & 0,2 & 0,21 & 0,1636 & 0,13 & 0,1 & 0,08 & 0,05 & 0,03 \\
\hline I & 0,1 & 0,16 & 0,15 & 0,1534 & 0,1598 & 0,14 & 0,1 & 0,05 & 0,02 \\
\hline \multicolumn{10}{|c|}{ SMAA-DEMATEL-GİA } \\
\hline & 㐫 & 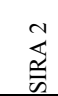 & $\stackrel{m}{\underset{\sigma}{\leftrightarrows}}$ & $\underset{\Xi}{\stackrel{\Xi}{\leftrightarrows}}$ & $\begin{array}{l}n \\
\stackrel{5}{=}\end{array}$ & $\begin{array}{l}0 \\
\underset{\Xi}{\leftrightarrows}\end{array}$ & $\underset{\Omega}{\stackrel{\Xi}{a}}$ & 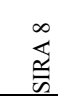 & $\underset{\nwarrow}{\leftrightarrows}$ \\
\hline $\mathrm{A}$ & 0,01 & 0,03 & 0,05 & 0,06 & 0,08 & 0,11 & 0,15 & 0,3 & 0,25 \\
\hline B & 0,07 & 0,11 & 0,13 & 0,14 & 0,1635 & 0,17 & 0,14 & 0,08 & 0,04 \\
\hline $\mathrm{C}$ & 0,26 & 0,15 & 0,12 & 0,1 & 0,09 & 0,07 & 0,07 & 0,07 & 0,11 \\
\hline $\mathrm{D}$ & 0,08 & 0,18 & 0,1956 & 0,1651 & 0,13 & 0,11 & 0,09 & 0,05 & 0,03 \\
\hline $\mathrm{E}$ & 0,42 & 0,15 & 0,11 & 0,1 & 0,08 & 0,06 & 0,06 & 0,03 & 0,03 \\
\hline $\mathrm{F}$ & 0,01 & 0,02 & 0,03 & 0,04 & 0,05 & 0,07 & 0,12 & 0,25 & 0,47 \\
\hline $\mathrm{G}$ & 0,01 & 0,04 & 0,07 & 0,1 & 0,14 & 0,2 & 0,24 & 0,17 & 0,07 \\
\hline $\mathrm{H}$ & 0,09 & 0,19 & 0,1998 & 0,17 & 0,13 & 0,1 & 0,08 & 0,05 & 0,02 \\
\hline I & 0,09 & 0,16 & 0,15 & 0,16 & 0,1606 & 0,14 & 0,1 & 0,05 & 0,02 \\
\hline
\end{tabular}

Elde edilen sira kabul edilebilirlik indisi Tablo 8'de ve merkezi ağırlık vektörleri ile güvenilirlik faktörleri de Tablo 9'da listelenmiştir. Yöntemlerin üçünde de "E" firması ilk sırada tercih edilmiştir. Fakat E alternatifinin ilk sırada seçilmesinin güvenilirlik faktörü değeri hem SMAA-GİA hem de SMAADEMATEL-GİA yöntemlerinde SMAA yöntemine göre daha yüksek çıkmıştır. Buda karar vericiye aldığı kararın daha tutarlı olduğu kanaatini sağlayabilir. SMAA' nın güvenilirlik faktörü değeri \%87 iken bu değer SMAA-GİA' da \%96'ya SMAA-DEMTELGİA' da ise daha da yükselerek \%97 sonucunu vermiştir.

Tablo 9. Güvenilirlik Faktörleri ve Merkezi Ağırlık Vektörleri (Central weight vectors and confidence factors)

\begin{tabular}{|c|c|c|c|c|c|c|}
\hline \multicolumn{7}{|c|}{ SMAA } \\
\hline & 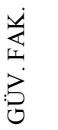 & 荘 & 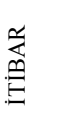 & 当 & $\begin{array}{l}\sum_{i=1}^{\dot{j}} \\
\sum_{\Sigma}\end{array}$ & $\frac{\mathscr{a}}{\mathscr{\approx}}$ \\
\hline $\mathrm{A}$ & 0,03 & 0,21 & 0,2 & 0,22 & 0,22 & 0,18 \\
\hline B & 0,01 & 0,21 & 0,2 & 0,22 & 0,19 & 0,19 \\
\hline $\mathrm{C}$ & 0 & 0 & 0 & 0 & 0 & 0 \\
\hline $\mathrm{D}$ & 0,02 & 0,21 & 0,19 & 0,24 & 0,21 & 0,18 \\
\hline $\mathrm{E}$ & 0,87 & 0,21 & 0,2 & 0,21 & 0,2 & 0,21 \\
\hline F & 0,03 & 0,2 & 0,21 & 0,2 & 0,21 & 0,21 \\
\hline G & 0,02 & 0,21 & 0,22 & 0,19 & 0,19 & 0,21 \\
\hline $\mathrm{H}$ & 0,03 & 0,2 & 0,2 & 0,2 & 0,21 & 0,21 \\
\hline I & 0,02 & 0,2 & 0,22 & 0,18 & 0,21 & 0,22 \\
\hline \multicolumn{7}{|c|}{ SMAA-GİA } \\
\hline A & 0,02 & 0,29 & 0,17 & 0,19 & 0,29 & 0,1 \\
\hline B & 0,3 & 0,15 & 0,14 & 0,16 & 0,44 & 0,14 \\
\hline $\mathrm{C}$ & 0,95 & 0,12 & 0,13 & 0,38 & 0,16 & 0,23 \\
\hline $\mathrm{D}$ & 0,3 & 0,16 & 0,15 & 0,15 & 0,19 & 0,38 \\
\hline $\mathrm{E}$ & 0,96 & 0,28 & 0,3 & 0,14 & 0,16 & 0,15 \\
\hline $\mathrm{F}$ & 0,02 & 0,49 & 0,13 & 0,16 & 0,13 & 0,11 \\
\hline $\mathrm{G}$ & 0,03 & 0,24 & 0,12 & 0,16 & 0,37 & 0,14 \\
\hline $\mathrm{H}$ & 0,32 & 0,18 & 0,15 & 0,15 & 0,18 & 0,36 \\
\hline $\mathrm{I}$ & 0,42 & 0,16 & 0,14 & 0,17 & 0,41 & 0,14 \\
\hline \multicolumn{7}{|c|}{ SMAA-DEMATEL-GİA } \\
\hline $\mathrm{A}$ & 0,02 & 0,1 & 0,29 & 0,17 & 0,36 & 0,11 \\
\hline $\mathrm{B}$ & 0,3 & 0,08 & 0,21 & 0,16 & 0,45 & 0,13 \\
\hline $\mathrm{C}$ & 0,96 & 0,07 & 0,18 & 0,39 & 0,15 & 0,24 \\
\hline $\mathrm{D}$ & 0,3 & 0,08 & 0,22 & 0,14 & 0,19 & 0,39 \\
\hline$E$ & 0,97 & 0,16 & 0,43 & 0,14 & 0,15 & 0,14 \\
\hline $\mathrm{F}$ & 0,01 & 0,12 & 0,47 & 0,27 & 0,08 & 0,08 \\
\hline $\mathrm{G}$ & 0,03 & 0,1 & 0,21 & 0,18 & 0,41 & 0,13 \\
\hline $\mathrm{H}$ & 0,31 & 0,09 & 0,23 & 0,14 & 0,18 & 0,39 \\
\hline $\mathrm{I}$ & 0,43 & 0,08 & 0,21 & 0,15 & 0,45 & 0,13 \\
\hline
\end{tabular}

\section{SMAA-GİA ve SMAA-DEMATEL-GİA} yöntemlerini karşılaştırdığımızda alternatiflerin sıralamasının çok benzer olduğu sadece 4. ve 5. sırada tercih edilen alternatiflerin farklı olduğu görülmektedir. SMAA-GİA' da 4. sirada D alternatifi yer alırken, SMAA-DEMATEL-GİA' da H alternatifi yer almaktadır. Aynı şekilde 5. sırada I alternatifi yerine $\mathrm{B}$ alternatifi yer almaktadır. Bu sonuçlara ek olarak kriter ölçülerin ortalaması kesin değer olarak varsayılıp kriter ağırlıkları da SMAA-GİA' dan elde edilen ortalama ağırlık değerleri kullanılarak GİA sonuçları elde edilmiştir. GİA sonuçları Tablo 10' da verilmiştir. GİA sonuçlarına göre de E alternatifi ilk sırada tercih edilmiştir. 
Tablo 10. GİA sonuçları ve Diğer Yöntemlerin Karşılaştırması (Results of GRA and Compare of Other Methods)

\begin{tabular}{|c|c|c|c|c|c|}
\hline \multirow{2}{*}{ 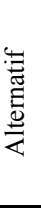 } & \multicolumn{2}{|c|}{ GİA } & \multirow{2}{*}{ 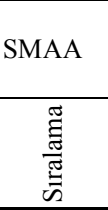 } & \multirow{2}{*}{ 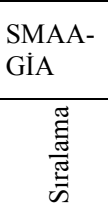 } & \multirow{2}{*}{ 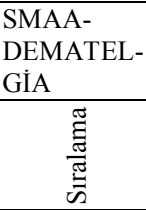 } \\
\hline & $r_{o i}$ & 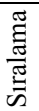 & & & \\
\hline A & 0,471 & 8 & & 8 & 8 \\
\hline B & 0,592 & 6 & 7 veya 8 & & 5 \\
\hline $\mathrm{C}$ & 0,619 & 3 & 9 & & \\
\hline $\mathrm{D}$ & 0,599 & 5 & & 4 & \\
\hline $\mathrm{E}$ & 0,660 & 1 & 1 & 1 & 1 \\
\hline $\mathrm{F}$ & 0,438 & 9 & & 9 & 9 \\
\hline G & 0,507 & 7 & 5 veya 6 & 6 veya 7 & 6 veya 7 \\
\hline $\mathrm{H}$ & 0,605 & 4 & 2 & 2 veya 3 & 2,3 veya 4 \\
\hline I & 0,637 & 2 & 3 veya 4 & 5 & \\
\hline
\end{tabular}

\section{SONUÇLAR (CONCLUSIONS)}

Yapılan çalışmada SMAA-2'yi temel alan, DEMATEL ve GIA yöntemlerinin kombinasyonu olan, iki yeni yöntem, SMAA-GİA ve SMAADEMATEL-GİA önerilmiştir. Önerilen yöntemlerin en önemli özelliği eksik bilgi içeren kriter ağırlıklarının ve değerlerinin, olasılık dağılımlarından herhangi birisine uyan rasgele değişkene dayanmasidir.

Bir karar problemi için hangi ÇKKV yönteminin daha makul ve güvenilir olduğunu söylemek kolay değildir. $\mathrm{Bu}$ nedenle alternatifleri daha mantıklı ve güvenilir bir şekilde sıralamanın yolu, aynı problemi birçok ÇKKV yöntemi ile çözüp daha sonra nihai sonuca karar vermektir [66]. Bu nedenle yapılan çalışmada karar vericilere farklı bir alternatif sunarak stokastik karar vermeye yardımcı olan, modelleme zorluklarını azaltan alternatif ve etkili bir yöntemin literatüre kazandırılması amaçlanmıştır.

Sonuçları orijinal verileri temel alan, hesaplamaları kolay ve anlaşılabilir bir yöntem olan GİA yönteminin SMAA yöntemi ile entegresi, GİA'nın ağırlık bilgisi olmadığı durumlarda ve belirsiz, kesin olmayan verilerle de kullanılabilmesine olanak tanımıştır. Aynı zamanda, kalitatif ve kantitatif kriterleri de eş zamanlı olarak dikkate alarak farklı kriterlerle de değerlendirilebilmesine imkan sağlamıştır.

SMAA-GİA yönteminin, kriterlerin bağımsız olmadığı ve birbirlerini etkilediği karar problemlerine de uygulanabilmesini sağlamak için, DEMATEL yöntemi ile de entegresi yapılmıştır. SMAA-GİA ve SMAA-DEMATEL-GİA yöntemleri diğer SMAA ve hibrit modelleri ile karşılaştırıldığında uygulanması daha basit ve fonksiyoneldir.
Gelecekte yapılacak olan çalışmalarda görsel ve kullanıcı dostu olan DEMATEL yönteminin, diğer hibrit SMAA yöntemleri, örneğin SMAA-D, SMAATRI, SMAA-TOPSIS v.s. ile de entegrasyonu mümkündür. Böylelikle diğer yöntemlerde de kriter bağımlılıkları, karar verme sürecinin etkinleştirilmesinde hesaba katılabilecektir.

\section{KAYNAKLAR (REFERENCES)}

1. Tzeng, G.H. ve Huang, J. J., Multiple Attribute Decision Making: Methods and Applications. CRC press, 2011.

2. Tabucanon, M.T., Multiple Criteria Decision Making in Industry, Elsevier Science Ltd, 1988.

3. Pohekar, S.D. ve Ramachandran, M., "Application of Multi-Criteria Decision Making to Sustainable Energy Planning a Review" Renewable and Sustainable Energy Reviews, Cilt 8, No 4, 365-381, 2004.

4. Saaty, T.L. "The Analytic Hierarchy Process: Planning, Priority Setting, Resources Allocation", New York, McGraw, 1980.

5. Tervonen, T. ve Figueira, J.R., "A Survey on Stochastic Multicriteria Acceptability Analysis Methods" Journal of Multi-Criteria Decision Analysis, Cilt 15, No 1-2, 1-14, 2008.

6. Lahdelma, R., Hokkanen, J. ve Salminen, P., "SMAA-Stochastic Multiobjective Acceptability Analysis" European Journal of Operational Research, Cilt 106, No 1, 137-143, 1998.

7. Charnetski, J.R., The Multiple Attribute Problem with Partial Information: The Expected Value and Comparative Hypervolume Methods, Doktora Tezi, Texas Üniversitesi, Austin, 1973.

8. Charnetski, J.R. ve Soland, R.M., "MultipleAttribute Decision Making with Partial Information: The Comparative Hypervolume Criterion" Naval Research Logistics Quarterly, Cilt 25, No 2, 279-288, 1978

9. e Costa, Bana C.A., "A Multicriteria Decision Aid Methodology to Deal with Conflicting Situations on the Weights" European Journal of Operational Research, 26.1, 22-34, 1986.

10. Figueira, J., Salvatore G. ve Matthias E., Multiple Criteria Decision Analysis: State of the Art Surveys, Springer Science \& Business Media, 2005.

11. Lahdelma, R. ve Pekka S., "SMAA-2: Stochastic Multicriteria Acceptability Analysis for Group Decision Making" Operations Research, Cilt 49, No 3, 444-454, 2001.

12. Hokkanen, J., Lahdelma, R., Miettinen, K. ve Salminen, P. "Determining the Implementation Order of a General Plan by Using a Multicriteria Method" Journal of Multi-Criteria Decision Analysis, Cilt 7, No 5, 273-284, 1998.

13. Lahdelma, R. ve Salminen, P., "Stochastic Multicriteria Acceptability Analysis Using the 
Data Envelopment Model", European Journal of Operational Research, Cilt 170, No 1, 241252, 2006.

14. Lahdelma, R., Miettinen $K$. ve Salminen $P$., "Ordinal Criteria in Stochastic Multicriteria Acceptability Analysis (SMAA)", European Journal of Operational Research, Cilt 147, No 1, 117-127, 2003.

15. Lahdelma, R. ve Salminen P., "Prospect Theory and Stochastic Multicriteria Acceptability Analysis (SMAA)", Omega, Cilt 37, No 5, 961971, 2009.

16. Tervonen, T., Figueira, J. R., Lahdelma, R., Dias, J. A. ve Salminen, P., "A Stochastic Method for Robustness Analysis in Sorting Problems", European Journal of Operational Research, Cilt 192, No 1, 236-242, 2009.

17. Okul, D., Gencer, C. ve Aydogan E.K., "A Method Based on SMAA-Topsis for Stochastic Multi-Criteria Decision Making and a RealWorld Application", International Journal of Information Technology \& Decision Making, Cilt 13, No 5, 957-978, 2014.

18. Tervonen, T. ve Lahdelma R., "Implementing Stochastic Multicriteria Acceptability Analysis", European Journal of Operational Research, Cilt 178, No 2, 500-513, 2007.

19. Félix, A., Baquerizo, A., Santiago, J. M. ve Losada, M. A., "Coastal Zone Management with Stochastic Multi-Criteria Analysis", Journal of Environmental Management, Cilt 112, 252266, 2012.

20. Kangas, A. S., Kangas, J., Lahdelma, R. ve Salminen, P., "Using SMAA-2 Method with Dependent Uncertainties for Strategic Forest Planning", Forest Policy and Economics, Cilt 9, No 2, 113-125, 2006.

21. Menou, A., Benallou, A., Lahdelma, R. ve Salminen, P., "Decision Support for Centralizing Cargo at a Moroccan Airport Hub Using Stochastic Multicriteria Acceptability Analysis", European Journal of Operational Research, Cilt 204, No 3, 621-629, 2010.

22. Durbach, I., Lahdelma, R. ve Salminen P., "The Analytic Hierarchy Process with Stochastic Judgements", European Journal of Operational Research, Cilt 238, No 2, 552-559, 2014.

23. Durbach, I. ve Davis S., "Decision Support for Selecting a Shortlist of Electricity-Saving Options: A Modied SMAA Approach", ORiON: The Journal of ORSSA, Cilt 28, No 2, 99-116, 2013.

24. Hokkanen, J., Lahdelma R. ve Salminen P., "A Multiple Criteria Decision Model For Analyzing And Choosing Among Different Development Patterns for the Helsinki Cargo Harbor", SocioEconomic Planning Sciences, Cilt 33 No 1,1-23, 1999.

25. Hokkanen, J., Lahdelma R. ve Salminen P., "Multicriteria Decision Support in a Technology
Competition for Cleaning Polluted Soil in Helsinki", Journal of Environmental Management, Cilt 60, No 4, 339-348, 2000.

26. Kangas, J., Hokkanen, J., Kangas, A. S., Lahdelma, R. ve Salminen, P., "Applying Stochastic Multicriteria Acceptability Analysis to Forest Ecosystem Management with both Cardinal and Ordinal Criteria", Forest Science, Cilt 49, No 6, 928-937, 2003.

27. Rocchi, L., "Using Stochastic Multi-Criteria Acceptability Analysis Methods in SEA: An Application to the Park of Trasimeno (Italy)", Journal of Environmental Planning and Management, Cilt 55 No 2, 177-189, 2012.

28. Lahdelma, R. ve Salminen P., "Ordinal Measurements with Interval Constraints in the EIA Process for Siting a Waste Storage Area", Real-time and Deliberative Decision Making, Springer Netherlands, 397-413, 2008.

29. Lahdelma, R., Salminen, P., Simonen, A. ve Hokkanen, J., "Choosing a Reparation Method for a Landfill by Using the SMAA-O Multicriteria Method", Multiple Criteria Decision Making in the New Millennium, Springer, Berlin Heidelberg, 380-389, 2001.

30. Makkonen, S., Lahdelma, R., Asell, A. M. ve Jokinen, A., "Multi-Criteria Decision Support in the Liberalized Energy Market", Journal of Multi-Criteria Decision Analysis, Cilt 2, No 1, 27-42, 2003.

31. Lahdelma, R. ve Salminen P., "The Shape of the Utility or Value Function in Stochastic Multicriteria Acceptability Analysis", OR Spectrum, Cilt 34, No 4, 785-802, 2012.

32. Ozmen, M. ve Aydogan, E. K. "Reverse Logistics Options Selection Problem: An Application of SMAA-2", 11. International Logistics \& Supply Chain Congress, Meliksah Üniversitesi, Nevşehir, 673-680, 07-09 112013.

33. Corrente, S., Figueira J.R. ve Greco S., "The SMAA-PROMETHEE Method", European Journal of Operational Research, Cilt 239, No 2, 514-522, 2014.

34. Tervonen, T., Barberis, G. F., Figueira, J. R. ve Escribano, M. C "Site Selection for a University Kindergarten in Madrid", Evaluation and Decision Models with Multiple Criteria. Springer, Berlin Heidelberg, 2015.

35. Tervonen, T., Hakonen, H. ve Lahdelma R., "Elevator Planning with Stochastic Multicriteria Acceptability Analysis", Omega, Cilt 36, No 3, 352-362, 2008.

36. Tervonen, T., Linkov, I., Figueira, J. R., Steevens, J., Chappell, M. ve Merad, M., "RiskBased Classification System of Nanomaterials", Journal of Nanoparticle Research, Cilt 11, No 4, 757-766, 2009.

37. Tervonen, T., Figueira, J., Lahdelma, R. ve Salminen, P., Modelling MCDA Group Preferences for Public Human Resource 
Management: Evaluating the Quality of Education at the Department of Information Technology, The University of Turku (Finland). Research Report 22/2004 of the Institute of Systems Engineering and Computers (INESC-Coimbra), Coimbra, Portugal, 2004.

38. Hillege, H. L., Buskens, E. ve Postmus, D., A State-of-the-Art Multi-Criteria Model for Drug Benefit-Risk Analysis, University of Groningen, 2010. http://drugis.org/files/tervonenantidep-SOM-final.pdf.

39. Aertsen, W., Kint, V., Van Orshoven, J. ve Muys, B., "Evaluation Of Modelling Techniques for Forest Site Productivity Prediction in Contrasting Ecoregions Using Stochastic Multicriteria Acceptability Analysis (SMAA)", Environmental Modelling \& Software, Cilt 26, No 7, 929-937, 2011.

40. Karabay, S., Köse E. ve Kabak M. "Stokastik Çok Kriterli Kabul Edilebilirlik Analizi ile Bir Kamu Kurumu için Tesis Yeri Seçimi/Facility Location Selection for A Public Organization by Stochastic Multi-Criteria Acceptability Analysis", Ege Akademik Bakış, Cilt 14, No 3, 361, 2014.

41. Atici, K.B., Simsek, A. B., Ulucan, A. ve Tosun, M. U., "A GIS-Based Multiple Criteria Decision Analysis Approach for Wind Power Plant Site Selection", Utilities Policy, 2015.

42. Deng, J.L., "Introduction to Grey System Theory", The Journal of Grey System, Cilt 1, No 1, 1-24, 1989.

43. Bai, C. ve Sarkis, J., "A Grey-Based DEMATEL Model for Evaluating Business Process Management Critical Success Factors", International Journal of Production Economics, Cilt 146, No 1, 281-292, 2013.

44. Kabak, M., "A Fuzzy DEMATEL-ANP Based Multi Criteria Decision Making Approach for Personnel Selection", Multiple-Valued Logic and Soft Computing, Cilt 20, No 5-6, 571-593, 2013.

45. Deng, J.L., "Control Problems of Grey Systems", Systems \& Control Letters, Cilt 1, No 5, 288294, 1982.

46. Çaydaş, U. ve Hasçalık A., "Use of the Grey Relational Analysis to Determine Optimum Laser Cutting Parameters with Multi-Performance Characteristics", Optics \& Laser Technology, Cilt 40, No 7, 987-994, 2008.

47. Yeh, M. ve Lu, H.C., "Evaluating Weapon Systems Based on Grey Relational Analysis and Fuzzy Arithmetic Operations", Journal of the Chinese Institute of Engineers, Cilt 23, No 2, 211-221, 2000.

48. Song, Q., Shepperd M. ve Mair C., "Using Grey Relational Analysis to Predict Software Effort with Small Data Sets", Software Metrics, 2005. 11th IEEE International Symposium, 10-35, Eylül 2005.
49. He, R.S. ve Hwang S.F., "Damage Detection by a Hybrid Real-Parameter Genetic Algorithm Under the Assistance of Grey Relation Analysis", Engineering Applications of Artificial Intelligence, Cilt 20, No 7,980-992, 2007.

50. $\mathrm{Xu}$, G., Tian, W., Qian, L. ve Zhang, X., "A Novel Conflict Reassignment Method Based on Grey Relational Analysis (GRA)", Pattern Recognition Letters, Cilt 28, No 15, 2080-208, 2007.

51. Jadidi, O., Sai Hong, T., Firouzi, F. ve Yusuff, R. M., "An Optimal Grey Based Approach Based on TOPSIS Concepts for Supplier Selection Problem", International Journal of Management Science and Engineering Management, Cilt 4, No 2, 104-117, 2009.

52. Özdemir, A.İ. ve Deste M., "Gri İlişkisel Analiz ile Çok Kriterli Tedarikçi Seçimi: Otomotiv Sektöründe Bir Uygulama”, İstanbul Üniversitesi İşletme Fakültesi Dergisi, Cilt 38, No 2, 147-156, 2009.

53. Qian, W. ve Li, L., "Research on Investment Decision-Making of Construction Engineering Projects Based on the Grey Relation Grade", Advanced Science Letters, Cilt 15, No 1, $407-$ 409, 2012.

54. Wu, W.W. ve Lee Y.T., "Developing Global Managers' Competencies Using the Fuzzy DEMATEL Method", Expert systems with Applications, Cilt 32, No 2, 499-507, 2007.

55. Fontela, E., Structural Analysis of the World Problematique: (Methods), Battelle Geneva Research Centre, 1974.

56. Fontela, E. ve Gabus A. "The DEMATEL Observer, DEMATEL 1976 Report. Switzerland, Geneva, Battelle Geneva Research Center. February 5, 2007” 1976.

57. Aksakal, E. ve Dağdeviren M., "ANP ve DEMATEL Yöntemleri ile Personel Seçimi Problemine Bütünleşik Bir Yaklaşım”, Journal of the Faculty of Engineering and Architecture of Gazi University, Cilt 25, No 4,2010.

58. Gabus, A. ve Fontela E., "World Problems, an Invitation to Further thought within the Framework of DEMATEL", Battelle Geneva Research Center, Geneva, Switzerland, 1972.

59. Greco, S., Ehrgott M. ve Figueira J.R., Trends in Multiple Criteria Decision Analysis, Springer Science \& Business Media, 2010.

60. Eroğlu, Ö., Bakım/Onarım Alternatiflerinin Bulanı DEMATEL ve SMAA-2 Yöntemleriyle Değerlendirilmesi, Yüksek Lisans Tezi, Gazi Üniversitesi, Fen Bilimleri Enstitüsü, Ankara, 2014.

61. Lahdelma, R., Makkonen S. ve Salminen P., "Multivariate Gaussian Criteria in SMAA", European Journal of Operational Research, Cilt 170, No 3, 957-970, 2006.

62. Lahdelma, R., Makkonen S. ve Salminen P., "Two Ways to Handle Dependent Uncertainties 
in Multi-Criteria Decision Problems", Omega, Cilt 37, No 1, 79-92, 2009.

63. Tsai, H.Y., Huang B.H. ve Wang A.S. "Combining AHP and GRA Model for Evaluation Property-Liability Insurance Companies to Rank", Journal of Grey System, Cilt 20, No 1, 2008.

64. Wu, H.H., "A Comparative Study of Using Grey Relational Analysis in Multiple Attribute Decision Making Problems", Quality Engineering, Cilt 15, No 2, 209-217, 2002.
65. Aydogan, E.K., "Performance Measurement Model for Turkish Aviation Firms Using the Rough-AHP And TOPSIS Methods Under Fuzzy Environment", Expert Systems with Applications, Cilt 38, No 4, 3992-3998, 2011.

66. Chan, L.K. ve Wu M.L., "Prioritizing the Technical Measures in Quality Function Deployment", Quality Engineering, Cilt 10, No 3, 467-479, 1998. 